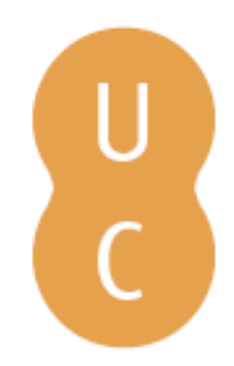

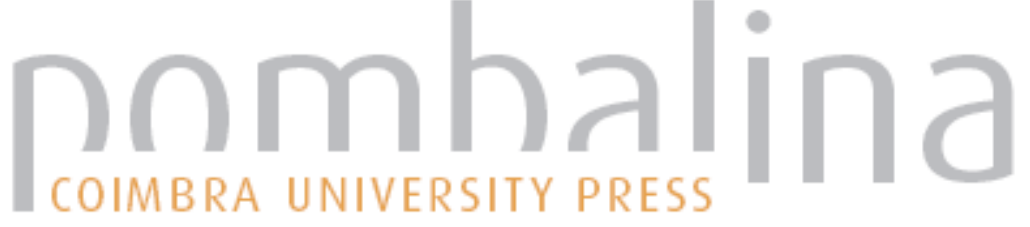

\section{Contributo para uma Geomorfologia Cultural do Maciço de Sicó}

\author{
Autor(es): $\quad$ Cunha, Lúcio \\ Publicado por: Imprensa da Universidade de Coimbra \\ URL \\ persistente: URI:http://hdl.handle.net/10316.2/43479 \\ DOI: $\quad$ DOl:https://doi.org/10.14195/978-989-26-1343-7_9
}

Accessed : $\quad$ 26-Apr-2023 11:38:19

A navegação consulta e descarregamento dos títulos inseridos nas Bibliotecas Digitais UC Digitalis, UC Pombalina e UC Impactum, pressupõem a aceitação plena e sem reservas dos Termos e Condições de Uso destas Bibliotecas Digitais, disponíveis em https://digitalis.uc.pt/pt-pt/termos.

Conforme exposto nos referidos Termos e Condições de Uso, o descarregamento de títulos de acesso restrito requer uma licença válida de autorização devendo o utilizador aceder ao(s) documento(s) a partir de um endereço de IP da instituição detentora da supramencionada licença.

Ao utilizador é apenas permitido o descarregamento para uso pessoal, pelo que o emprego do(s) título(s) descarregado(s) para outro fim, designadamente comercial, carece de autorização do respetivo autor ou editor da obra.

Na medida em que todas as obras da UC Digitalis se encontram protegidas pelo Código do Direito de Autor e Direitos Conexos e demais legislação aplicável, toda a cópia, parcial ou total, deste documento, nos casos em que é legalmente admitida, deverá conter ou fazer-se acompanhar por este aviso. 


\section{FERNANDA CRAVIDÃO}

\section{IÚCIO CUNHA}

PAULA SANTANA

\section{NORBERTOSANTOS}

(ORG.)

\section{ESPAÇOS E TEMPOS EM GEOGRAFIA}

HOMENAGEM A ANTÓNIO GAMA

IMPRENISA DÁ UNIVERSIDADE DE COIMBRA COIMBRA UNIVERSITY PRESS

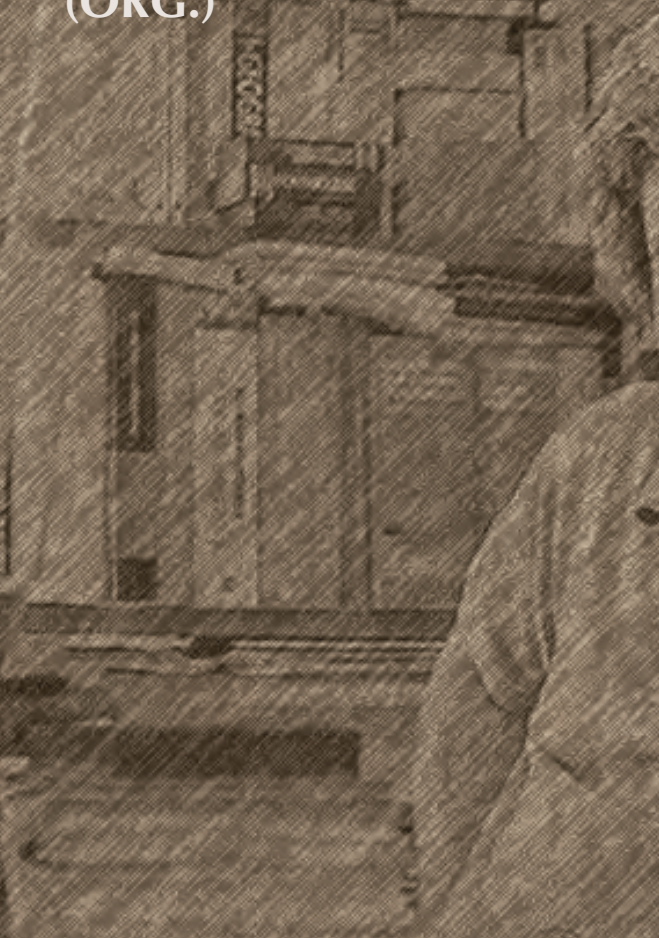




\section{CONTRIBUTO PARA UMA \\ GEOMORFOLOGIA CULTURAL DO MACIÇO DE SICÓ}

\section{Lúcio Cunha/luciogeo@ci.uc.pt}

CEGOT e Departamento de Geografia e Turismo. Faculdade de Letras da Universidade de Coimbra

\section{Introdução}

Conheci António Gama Mendes nos bancos da Faculdade de Letras da Universidade de Coimbra. Eu iniciava e ele terminava a Licenciatura em Geografia. Fomos colegas enquanto estudantes, ainda fui seu aluno, voltámos a ser colegas, enquanto professores e investigadores de Geografia, e ao longo de mais de 40 anos construímos e desenvolvemos, em conjunto com um grupo grande de outros colegas, um espírito de forte camaradagem, uma amizade profunda, uma colaboração que, para mim, se tornou muito intensa e enriquecedora, ajudando-me a crescer como pessoa e como geógrafo.

Como é sabido, António Gama Mendes teve uma carreira académica, tanto do ponto de vista científico como do ponto de vista pedagógico, ligada essencialmente a temas de História e Teoria da Geografia, Geografia Social, Geografia Cultural, Geografia Urbana, Geografia do Lazer e dos Tempos Livres, Geografia das Fronteiras, em síntese percorrendo um pouco todos os temas de Geografia Humana, interligando-os, integrando-os, problematizando-os e procurando articulaçóes interdisciplinares que buscassem uma mais eficaz interpretação dos territórios e das sociedades que os constroem. No entanto, António Gama 
Mendes, o Gama, como era conhecido por quase todos, iniciou a sua carreira científica com um trabalho de Geografia Física sobre os Tufos de Condeixa que lhe serviu de tese de licenciatura (Mendes, 1974), mais tarde revisto, actualizado e republicado na Revista Cadernos de Geografia (1985). Um excelente trabalho de articulação entre a leitura teórica da dinâmica cársica e especificamente da construção dos diferentes corpos e fácies de tufos calcários e o trabalho empírico muito assente num exaustivo trabalho de campo que procurava fazer sempre acompanhado, para poder conversar, discutir, eventualmente apenas expor em voz alta, as suas questóes, dúvidas ou conclusóes. Mais de 40 anos depois de escrito na sua versão original, este texto ainda se mantém como um trabalho de referência, incontornável nos estudos sobre tufos calcários em Portugal, e particularmente no estudo do maior afloramento em território nacional, o dos Tufos de Condeixa, apesar de alguns outros textos terem sido depois publicados sobre o tema e sobre a área (Cunha, 1988; Soares et al., 1997 a, b).

No trabalho publicado em 1985 inclui uma dedicatória, que pretendia ser também um modo de homenagem ao seu orientador, o Professor Alfredo Fernandes Martins, então recentemente falecido, onde escreve "Porque o essencial do ensino dos Mestres não são as matérias, mas o método, a formulação dos problemas, a humildade perante o erro”, princípios que António Gama haveria de tornar seus, norteando a sua vida de professor e de investigador em Geografia.

Deste tempo recordo dois aspectos fundamentais:

O são convívio com estudantes e com os colegas mais novos, que nos levou muitas vezes a ver o "Nascer do Sol" no Penedo da Saudade, na Sra do Circo (Maciço de Sicó) ou nos Penedos de Góis (Serra da Lousã). Quase sempre, António Gama conduzia estes convívios de amigos para intensas e profícuas discussôes de grupo, em torno da Geografia e do seu valor como Ciência, bem como das diversas geografias da região de Coimbra, a cujo conhecimento nos estimulava, mesmo que durante deslocaçóes noturnas, adivinhando mais que olhando, sentindo mais que vendo, paisagens, territórios, lugares, redes, relações: Geografias!

Ensinou a necessidade de articular informação teórica, lida e compreendida através de livros e revistas em língua castelhana, francesa ou inglesa, com a 
informação de carácter mais prático recolhida em observação direta de campo, em inquéritos ou em dados estatísticos. Talvez mais que articular se deva dizer antecipar, pois muitas vezes quando tentávamos impor-lhe a importância do trabalho de campo, o mito da descoberta do afloramento particular ou da forma especial como chaves para a interpretação de um problema geográfico, a resposta, sempre pronta era "só encontraremos o que soubermos procurar" ou, de modo mais simples e sintético, "só veremos o que soubermos ver".

E era vê-lo no cimo de um penhasco de braços abertos, numa figura de recorte místico, rodando o corpo à procura da direção exata de um alinhamento tectónico marcado no relevo ou de indicador apontado a aldeias ou campos, ajudando a construir o mapa mental de espaços rurais das montanhas dos arredores de Coimbra.

Depois, o tempo foi responsável pelo afastamento de interesses disciplinares, um dirigindo-se para a Epistemologia da Geografia e para a Geografia Humana, outro para a Geomorfologia, foram tempos de crescimento e de maturaçáo científica, em que outras qualidades do Gama marcavam o quotidiano relacional no seio do Grupo de Geografia da Universidade de Coimbra: o entusiasmo e a generosidade. Entusiasmo que marcava os momentos em que encontrava e generosamente cedia o artigo sobre um qualquer carso num qualquer dos quatro cantos do mundo que tivesse ou pudesse ter alguma relaçáo com o carso do Maciço de Sicó. Entusiasmo que se refletia também nos contactos que me proporcionou com colegas de outras universidades nacionais e estrangeiras, sempre na generosa perspetiva de abrir as portas certas para um melhor desempenho dos mais novos. Finalmente, o entusiasmo, com que nos passava muito do seu saber em viagens de estudo que guiava magistralmente: muito mais do que por aquilo que transmitia, o modo entusiasmado e contagiante como a todos fazia sentir e perceber os papéis do meio físico e da sociedade, da história e da geografia, do rural e do urbano, do local, do regional e do nacional, na construção de uma Geografia bem percetível, atual e útil.

Por isso, o Gama nos falta e, me falta, a mim, particularmente.

O Maciço de Sicó, a cujo estudo tenho dedicado algum tempo nos últimos anos, foi-me também ensinado por ele. Nos tufos de Condeixa, na Senhora 
do Circo, no Furadouro e no Casmilo. Esta é a razão para ter escolhido como contributo para esta homenagem um pequeno texto de carácter metodológico sobre a avaliação do Património Geomorfológico Cársico no Maciço de Sicó, tentando cruzar alguns pontos de interesse territoriais e científicos comuns.

\section{Património geomorfológico no contexto dos estudos sobre Geopatrimónio: problemas conceptuais e operacionais}

Embora desde sempre o Ser Humano tenha valorizado as formas de relevo e outros elementos do meio natural abiótico numa perspetiva cultural, educativa e mesmo económica, pode dizer-se que os estudos sobre a importância da geodiversidade (Sharples, 2002, citado por Gray, 2004), geopatrimónio, geoconservaçáo e geoturismo são relativamente recentes e desenvolvem-se sobretudo já no século xxi pela mão de geólogos, geógrafos e turismólogos na busca das relaçóes entre os elementos patrimoniais naturais abióticos e os dados científicos que suportam o seu conhecimento e valorização, que justificam o seu significado ecológico, social e cultural e que proporcionam a sua divulgaçáo e os mecanismos de conservação adequados.

O conceito de geodiversidade, claramente estabelecido para responder à importância crescente e socialmente dominadora do conceito de biodiversidade, diz respeito ao conjunto e à diversidade de elementos, sistemas e processos geológicos (rochas), geomorfológicos (formas de relevo) e pedológicos (solos) (Sharples, 2002 e Australian Heritage Commission, 2002, citados por Grey (2004).

$\mathrm{O}$ conceito de Geopatrimónio (tradução do termo inglês geoheritage) corresponde ao conjunto de elementos naturais abióticos existentes à superfície da Terra (emersos ou submersos) que devem ser preservados devido ao seu valor patrimonial. Nesta definição, o Geopatrimónio inclui o Património Geológico, o Património Geomorfológico, o Património Hidrológico, o Património Pedológico, entre outros (Rodrigues e Fonseca, 2008).

Finalmente, por Património Geomorfológico pode entender-se o conjunto de elementos geomorfológicos (formas de relevo e depósitos correlativos, atuais e 
passadas, vistos a diferentes escalas), com interesse científico, pedagógico, cultural ou estético (Panizza, 2001; Reynard, 2005; Reynard e Panizza, 2005) que, pelo seu significado relevante, merece ser estudado, preservado e valorizado.

Associados, e tendo na composição das palavras o mesmo prefixo geo-, surgem também os conceitos de geoconservaçáo e de geoturismo. A geoconservação tem como objetivo a preservação da diversidade natural (ou geodiversidade) de aspetos e processos geológicos (substrato), geomorfológicos (formas da paisagem) e do solo significativos, mantendo a evolução natural (velocidade e intensidade) desses aspetos e processos (Sharples, 2002, citado por Brilha, 2005).

Por seu turno, o conceito de geoturismo, proposto por Hose em 1995, corresponde à "provisão de serviços e facilidades interpretativas, no sentido de possibilitar aos turistas a compreensáo e aquisiçấo de conhecimentos de um sítio geológico ou geomorfológico, ao invés da sua simples apreciação estética” (Hose, 1995, citado por Moreira, 2011).

Para a análise e interpretação destes conceitos, muitas outras definiçóes de alguns outros autores poderiam ser apontadas. Tratando-se de uma área do conhecimento que só muito recentemente foi incorporada às Ciências da Terra $\mathrm{e}$ às Ciências Sociais e que envolve, em regra, uma abordagem interdisciplinar (Geologia; Geografia; Arqueologia; Turismo), é natural que surjam alguns problemas e até mesmo alguns conflitos de ordem conceptual. Um dos mais comuns é o da associaçáo ou confusáo dos conceitos acima referidos de geodiversidade, geopatrimónio, geoconservação e geoturismo com os conceitos de diversidade geológica, património geológico, conservação geológica ou turismo geológico, levando por consequência à inclusão do património geomorfológico dentro do chamado património geológico, como pretendem alguns investigadores da área científica da Geologia, algumas associaçôes profissionais de geólogos ou mesmo alguns serviços oficiais de gestão patrimonial em vários países do Mundo.

De facto, não sendo fácil a "arrumação" dos diferentes ramos do saber nos grandes grupos científicos, sobretudo em tempos marcados por uma forte interdisciplinaridade nas abordagens mais gerais, como é o caso dos estudos sobre o património, parece-nos mais interessante e realista manter os objetos geológico e geomorfológico distintos e sem subordinação entre si, ainda 
que ambos associados e incluídos dentro do grande "chapéu" das Ciências da Terra, ou seja da geodiversidade, do geopatrimónio, da geoconservação e do geoturismo.

De facto, o património geomorfológico merece ser classificado como um elemento autónomo face ao património geológico por diferentes razóes, de que se expóem aqui apenas as duas principais:

A Geomorfologia e, consequentemente as formas de relevo, são estudadas por várias ciências, nomeadamente pela Geografia Física e pela Geologia, com diferentes leituras dos processos que conduzem à construção das formas de relevo, sua associação e localização. Embora a Geomorfologia possa ser considerada como fazendo parte da Geologia, ela faz também parte da Geografia Física, logo da Geografia, bem como de outras ciências como a Engenharia e a Arqueologia. O património geomorfológico pode ser estudado em qualquer destes contextos científicos. Não tem, por isso, sentido incluí-lo como parte do património geológico (com estatuto semelhante ao do património mineralógico ou paleontológico), do mesmo modo que não tem significado considerá-lo como fazendo parte do património geográfico (com estatuto semelhante ao do património biogeográfico, ao património rural construído ou imaterial, ao património urbanístico das principais cidades ou ao património industrial, etc.).

Por outro lado, existe claramente um papel diferenciador e diferenciado do património geomorfológico face aos restantes tipos de geopatrimónio. Por exemplo, a grande articulação das formas de relevo com os Seres Humanos (pelo valor cultural e religioso do relevo: montes; grutas; praias) e, sobretudo, pela sua mais fácil perceção estética (espetacularidade; grandiosidade; beleza; diversidade), proporcionam uma maior aceitação do seu valor patrimonial pelo grande público e, mesmo, uma maior utilização em termos geoturísticos. Daí que mais de metade dos 61 elementos referidos no livro sobre "património geológico - geossítios a visitar em Portugal” (Brilha e Pereira, 2011) sejam

\footnotetext{
${ }^{1}$ A que melhor teria sido chamar "Geopatrimónio a visitar em Portugal", um pouco à semelhança do livro "Geoheritage in Europa and its conservation", livro de características semelhantes organizado à escala da Europa por Wimbledon e Smith-Meyer (2012).
} 
efetivamente elementos do património geomorfológico (como o vale glaciário do Zêzere, o inselberg de Monsanto, a arriba fóssil da Costa da Caparica ou a praia de Porto Santo).

Assim, por razóes conceptuais, mas também para evitar naturais leituras e conflitos disciplinares é preferível utilizar o prefixo geo- e o termo geopatrimónio, em vez do termo património geológico (aliás, tal como em geodiversidade, geoconservação e geoturismo). Uma outra vantagem desta utilizaçáo está no facto de que, embora por comodidade de análise, tenhamos de segmentar a realidade patrimonial, quase sempre um geossítio, uma área ou uma paisagem valem pelo conjunto de características que o definem (quanto menor a escala, maior a complexidade de características envolvidas). Um exemplo entre muitos outros semelhantes: o conhecido "Vale das Buracas" no Maciço de Sicó vale patrimonialmente pelos alinhamentos de abrigos sob rocha e pelos afloramentos de depósitos de vertente com crioclastos que justificam muita da evolução daquelas formas (Geomorfologia, o seu valor patrimonial principal), que dependem claramente dos tipos litológicos de calcário e da sua disposição estrutural (Geologia), que têm vertentes revestidas de uma vegetação rara e peculiar (Botânica; Ecologia), que terão abrigado seres humanos em tempos do Paleolítico Superior (Arqueologia) e que, ainda até há poucos anos atrás, davam abrigo a rebanhos e a pastores, numa ocupação marcada hoje não só por vestígios físicos, mas também por lendas e tradiçóes rurais. A aplicação dos conceitos de geopatrimónio, geoconservação e geoturismo parece vantajosa também pela capacidade de agregar, relacionar e tornar sistémica (geossistémica) a relação dos vários elementos patrimoniais presentes, sobretudo quando se trata de elementos patrimoniais à escala da área ou da paisagem.

No entanto, a argumentação acima exposta de modo perigosamente simplista, pretende apenas chamar a atenção para a necessidade de colaboração interdisciplinar nos estudos sobre o Geopatrimónio e, particularmente, entre geólogos, geógrafos e arqueólogos, integrando métodos de observação, inventariação e classificaçáo de elementos patrimoniais, bem como acautelando, com base nas respectivas experiências e nas competências específicas, as tarefas de geoconservação, divulgação e valorização, através do geoturismo. 


\section{Geopatrimónio cársico do Maciço de Sicó - Aplicação de uma metodologia para avaliaçáo}

O Maciço de Sicó (Cunha, 1988) é um maciço calcário carsificado através de processos paleocársicos de profundidade e de superfície, cujo geopatrimónio, essencialmente ligado aos processos geomorfológicos cársicos que deram origem às suas formas de relevo a diferentes escalas, tem vindo a ser dado a conhecer em diferentes trabalhos (Cunha e Vieira, 2004; Vieira e Cunha, 2006; Silva, 2012; Cunha et al., 2014).

Através destes e de outros trabalhos foram inventariados e descritos cerca de uma centena de elementos do património cársico, quase sempre de origem geomorfológica. Estes elementos foram cartografados, divulgados e integrados em possíveis percursos temáticos de visita. Todos estes processos têm sempre por base, explícita ou implicitamente, uma metodologia de avaliação dos elementos patrimoniais que permita selecionar de entre a vasta e rica geodiversidade do Maciço, os elementos patrimoniais mais significativos, mais ricos e mais valiosos, para os proteger e valorizar.

Neste caso específico foi ensaiado um método de avaliação que, ao contrário das habituais fichas de quantificação preenchidas, de modo que se pretende objetivo, por um único investigador, teve por base as respostas necessariamente subjetivas a um inquérito por um conjunto de pessoas que conhecem a realidade em causa. Foi feito um inquérito aberto, lançado através da internet, quer a alunos e ex-alunos do Departamento de Geografia e Turismo que visitaram e conhecem o Maciço de Sicó, bem como a membros de um grupo fechado do Facebook que tem como objetivo a discussão de diferentes aspetos ambientais, económicos e sociais do Maciço de Sícó. Os resultados agora apresentados são claramente preliminares, com significado estatístico pouco relevante e cujo objetivo fundamental é o de tentar experimentar um método distinto para avaliaçáo de elementos do geopatrimónio. Foram obtidas 118 respostas, das quais apenas 82 foram validadas por terem cumprido resposta a todos os itens. Foi proposta a avaliação através de uma escala de 5 termos dos 22 elementos geopatrimoniais considerados mais relevantes no Maciço de Sicó (Quadro I) 
tendo em consideração o seu valor científico, estético, cultural, pedagógico-didático e, numa tentativa de síntese, o valor global. Foi também solicitada aos inquiridos uma avaliaçáo das potencialidades destes elementos geopatrimoniais em termos de utilização turística e de lazer, desportiva, económica e pedagógico-didática. Os elementos patrimoniais foram considerados a várias escalas, desde a escala do sítio (exsurgências; grutas; dolinas) à escala da paisagem (montes; escarpas; vales; superfície dos tufos de Condeixa), passando por uma escala intermédia (em que foram incluídos os campos de lapiás; Carvalho, 1999; Cunha e Vieira, 2004)

Numa breve caracterização, os inquiridos são maioritariamente mulheres (52\%), têm uma idade que vai dos 18 aos 60 anos, mas com forte predomínio entre os 25 e os 50 anos (71\%), habilitaçóes literárias ao nível ou acima da licenciatura (83\%) e com residência em várias regiôes do país e 35\% a residir em municípios que integram o Maciço de Sicó.

Os resultados (Quadro I) mostram aparentemente a justeza das escolhas previamente efetuadas e apresentadas aos inquiridos. Por um lado, apenas 16\% dos inquiridos manifestaram o conhecimento de outros elementos geopatrimoniais não incluídos no inquérito (de que são exemplos as Fórnias da Ucha e de Casal Soeiro; Exsurgência da Lapinha; Serra do Rabaçal; alguma dolinas antropizadas e transformadas em lagoas; Lapas de Eira Pedrinha) e, por outro, todos os elementos considerados obtiveram uma pontuação (numa escala de 1 a 5) superior a 3,8, sendo que em apenas 3 casos (Olho do Tordo; Olhos do Dueça e Dolina do Peixeiro) não se atingiu o valor de 4. 


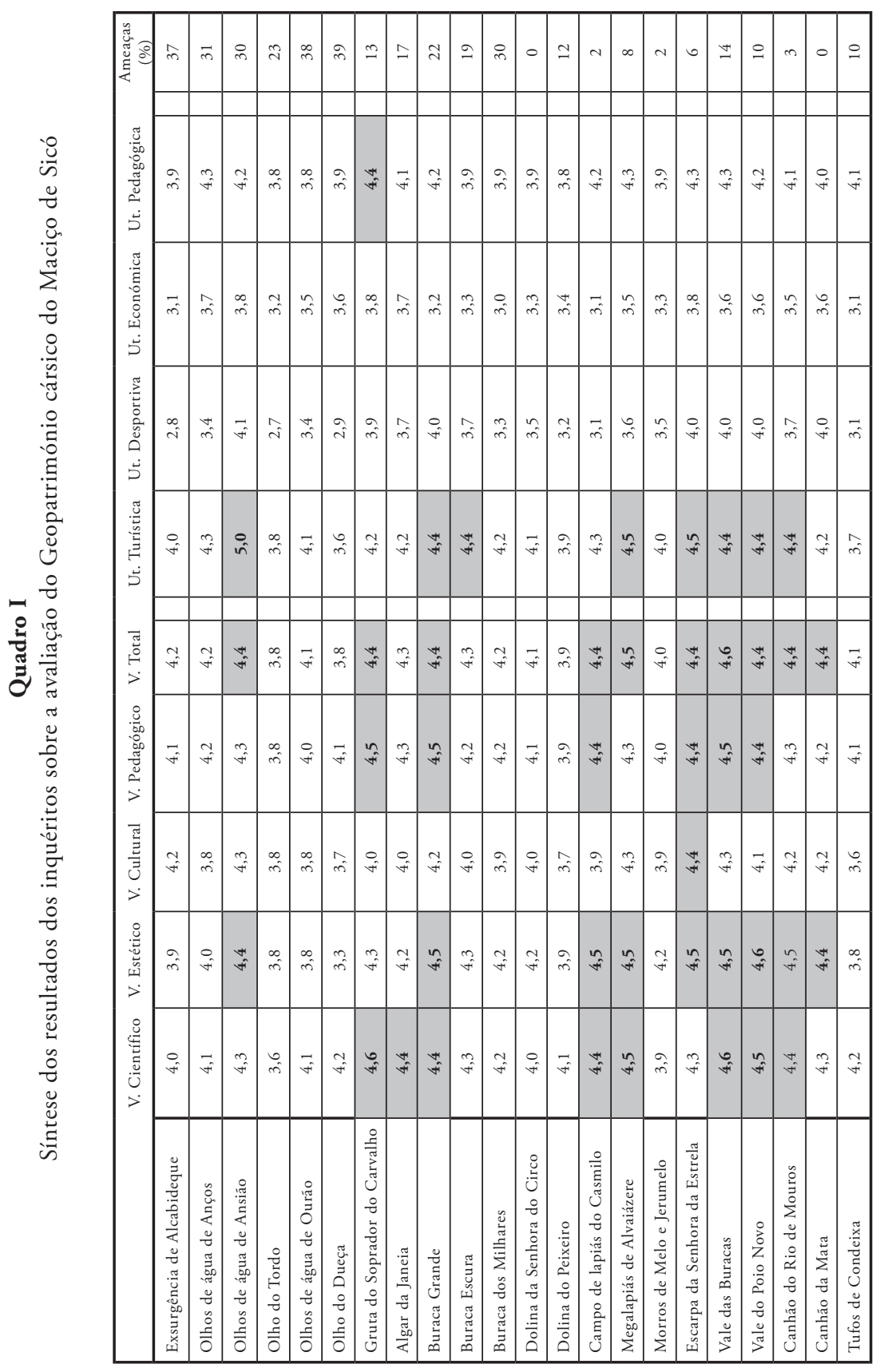


No plano científico os elementos patrimoniais mais relevantes parecem ser as grutas, os campos de lapiás e os canhōes fluviocársicos (Buracas; Poio Novo e Rio dos Mouros). No plano estético o leque de elementos patrimoniais valiosos alarga-se à Exsurgência dos Olhos de Água de Ansiáo, que recentemente foi alvo de obras de beneficiação turística, e às paisagens da escarpa da $\mathrm{Sr}^{\mathrm{a}}$ da Estrela e do canhão da Mata, sendo preteridas as grutas do Soprador do Carvalho e do Algar da Janeia. No plano cultural, a grande referência é a escarpa da $\mathrm{Sr}^{\mathrm{a}} \mathrm{da}$ Estrela pela capelinha homónima e pela peregrinação anual que a ela é feita. No plano pedagógico-didático os elementos geopatrimoniais a salientar aproximam-se dos da lista daqueles com valor científico (grutas do Soprador do Carvalho e Buraca Grande; campo de lapiás do Casmilo; escarpa da Sra da Estrela; Vales das Buracas e do Poio). Numa tentativa de síntese foi também solicitada uma apreciação do valor global de cada um dos elementos geopatrimoniais propostos. Salientam-se dez elementos, a exsurgência dos Olhos de Água de Ansião, as grutas do Soprador do Carvalho e da Buraca Grande, os dois campos de lapiás referidos, a escarpa da $\mathrm{Sr}^{\mathrm{a}}$ da Estrela e os canhóes fluviocársicos.

Tendo em consideração os modos práticos de utilização deste geopatrimónio é ressaltada a sua utilizaçáo no plano turístico e de lazer. Os inquiridos ressaltam oito destes elementos como tendo interesse geoturístico, no entanto não valorizam nem do ponto de vista económico, nem dos pontos de vista desportivo ou, sequer, do ponto de vista pedagógico, o património cársico de Sicó (apenas a gruta do Soprador do Carvalho entraria nesta última categoria). Aliás este é um caso muito curioso no contexto do geopatrimónio de Sicó. Desde a sua descoberta nos finais do século passado, esta cavidade pelo seu interesse científico, pedagógico e estético (particularmente por ser uma gruta ativa, com um rio subterrâneo a percorrê-la) tem sido alvo de uma constante tentativa de utilização turística, que acontece desde há cerca de dois anos, com impactes por estudar nas suas características geomorfológicas, climáticas e bióticas. Ora, os inquiridos atribuem-lhe valor científico e pedagógico, entendem, inclusivamente, que é uma cavidade com interesse pedagógico, mas năo lhe atribuem o valor turístico (desportivo) com que os responsáveis municipais entenderam valorizá-la. 
A perceção das ameaças à conservação dos elementos geopatrimoniais por parte dos inquiridos revela uma situaçáo confortável, uma vez que para todos os elementos geopatrimoniais foram sempre menos de $40 \%$ dos inquiridos a considerá-los ameaçados. Realce-se, no entanto, que as exsurgências cársicas sáo os elementos considerados como mais ameaçados, nomeadamente, as exsurgências do Olho do Dueça, do Ouráo e de Alcabideque.

\section{Conclusão}

Pretendeu-se, com este texto, o impossível: de modo simples, curto e despretensioso homenagear um amigo, um homem grande, inteligente, culto e cientificamente sofisticado que um dia, longínquo no tempo, se interessou pela Geografia Física e pelo Maciço de Sicó, antes de fazer uma carreira brilhante por temas geográficos de cariz mais epistemológico, político, cultural e social. Ainda assim, pretendeu-se uma apresentação que valorizasse os territórios de Sicó e os seus elementos geopatrimoniais ligados à geomorfologia cársica. Seguindo as liçôes de António Gama, pretendeu-se discutir mais os métodos que as matérias, deixar mais dúvidas que descrever certezas e levantar mais problemas que apresentar resultados.

Num carso como o do Maciço de Sicó, a importância dos processos antigos (paleocársicos), ligados a sucessivas evoluçóes geomorfológicas sob coberturas sempre incompletamente exumadas, torna natural que as formas fluviocársicas tenham um importante significado geomorfológico e patrimonial. Os vales das Buracas, dos Poios, da Mata e do Rio dos Mouros, testemunham esse valor. Por seu turno, são pouco frequentes as depressóes fechadas (como as dolinas) e os campos de lapiás, que apenas têm significado nos locais mais expostos e exumados do Maciço. Daí também a sua fraca expressão do ponto de vista patrimonial. Como cobertura gresosa náo significa exatamente fossilizaçáo, o carso subterrâneo continua a evoluir. Se do ponto de vista geomorfológico são algumas centenas as cavidades desigualmente distribuídas pelo Maciço e se, no seu conjunto, o carso subterrâneo constitui um dos principais valores 
geopatrimoniais do Maciço, as dificuldades de acesso fazem com que apenas algumas destas cavidades sejam conhecidas do grande público e tenham um significado geopatrimonial efetivo.

O exercício metodológico aqui ensaiado é, como foi dito, claramente preliminar. Com base nesta experiência será possível corrigir (ampliando) a lista de elementos geopatrimoniais, distinguindo-os do ponto de vista escalar e promovendo associaçôes com elementos do património biológico e cultural. Pretende-se, também, recolher a opinião de alguns atores municipais e regionais com responsabilidades sobre este território (incluído parcialmente na rede Natura 2000), bem como alguns agentes turísticos e desportivos com atuação em Sicó. Finalmente, será possível cruzar as perceçôes dos inquiridos com os seus perfis (locais, turistas ou investigadores; agentes e atores locais; etc.) no sentido de ajudar a perspetivar políticas de desenvolvimento local sustentáveis para um território que, apesar de situado no litoral do país, apresenta muitas limitaçôes características dos espaços interiores de baixa densidade.

\section{Bibliografia}

Brilha, José (2005). Património geológico e geoconservação - a conservação da natureza na sua componente geológica. Braga, Palimage, 190 p.

Brilha, José \& Pereira, Paulo (2011). Património geológico - Geossitios a visitar em Portugal. Braga, $137 \mathrm{p}$.

Carvalho, A. M. Galopim (1999). Geomonumentos. Lisboa, 30 p.

Cunha, L.; Dimuccio, L. \& Aubry, T. (2014). Património cársico no Centro de Portugal. O caso do Maciço de Sicó. Actas do I Encontro luso-brasileiro de Património Geomorfológico e Geoconservaçâo, Coimbra, pp. 27-34.

Cunha, Lúcio (1988). As serras calcárias de Condeixa-Sicó-Alvaiàzere. Estudo de Geomorfologia. Dissertação de Doutoramento, Coimbra, 329 p.

Cunha, Lúcio \& Vieira, António (2004). Património geomorfológico, recurso para o desenvolvimento local em espaços de montanha. Exemplos no Portugal Central. Cadernos de Geografia, Coimbra, 21/23, pp. 15-28.

Gray, Murray (2004). Geodiversity - Valuing and conserving abiotic nature. Chichester: Wiley, $434 \mathrm{p}$.

Mendes, A. Gama (1974). Os Tufos de Condeixa. Morfologia da área dos Tufos de Condeixa. Dissertação de Licenciatura, Coimbra.

Mendes, A. Gama (1985). Os Tufos de Condeixa. Estudo de Geomorfologia. Cadernos de Geografia, Coimbra, 4, pp. 53-119. 
Moreira, J. C. (2011). Geoturismo e interpretação ambiental. Ponta Grossa, Editora UEPG, 157 p.

Rodrigues, M. L. \& Fonseca, A. P. (2008). A valorizaçáo do geopatrimónio no desenvolvimento sustentável de áreas rurais. Colóquio Ibérico de Estudos Rurais, Coimbra.

Silva, Carlos (2012). Sicó: a dimensão cultural das paisagens: um estudo de turismo nas suas vertentes cultural e natureza. Dissertação de Doutoramento, Coimbra.

Soares, A. F.; Cunha, L. \& Marques, J. F. (1997). Les tufs calcaires dans la région du Baixo Mondego (Portugal) - Les tufs de Condeixa. Présentation génerale. Études de Géographie Physique, Traveaux 1997, Supll. n. ${ }^{\circ}$ XXVI, Aix-en-Provence, pp. 55 - 58.

Soares, A. F.; Cunha, L. \& Marques, J. F. (1997). Les tufs calcaires de Condeixa. Présentation générale et encadrement dans le modèle géomorphologique du Bas Mondego (Portugal). Não publicado.

Vieira, António \& Cunha, Lúcio (2006). Património geomorfológico - de conceito a projecto. O Maciço de Sicó. Publicaçōes da Associaçāo Portuguesa de Geomorfólogos, Vol. 3, APGeom, 2006, pp. 147-153.

Wimbledon, W. A. P. \& SMITH-Meyer, S. (2012). Geoheritage in Europe and its conservation. Progeo, Oslo, $405 \mathrm{p}$. 